
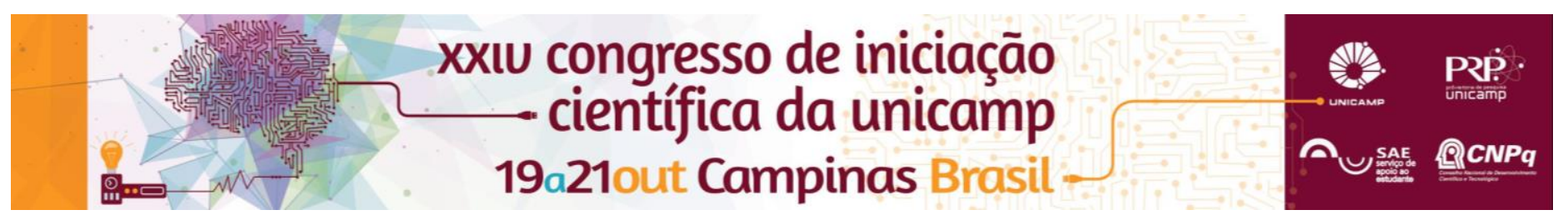

\title{
Avaliação da eficiência de uma wetland construída em escala experimental na remoção de matéria orgânica e fósforo no pós tratamento de efluentes domésticos.
}

\author{
Edgard Yassue*, Elaine C. C. Poletti, Marta S. G. Pires.
}

\section{Resumo}

Os efluentes domésticos necessitam de tratamento antes de seu lançamento nos corpos d'água, caso contrário podem comprometer sua qualidade. No entanto mesmo após o tratamento nem sempre esses efluentes se enquadram nos padrões de qualidade para lançamento e necessitam de pós tratamento. As wetlands construídas são alternativas de pós tratamento de efluentes de baixo custo de construção e manutenção, pois não necessitam de eneria elétrica e aplicação de produtos químicos. Esse sistema de tratamento pode ser utilizado tanto no tratamento, quanto no pós tratamento de efluentes.

Palavras-chave: Terras alagadas construídas, remoção de nutrientes, modelagem matemática.

\section{Introdução}

'Wetland' é um sistema composto por um leito preenchido com substrato e plantas aquáticas, responsável pela remoção da matéria orgânica e nutrientes, e pode ser usado no tratamento de esgotos ${ }^{1}$.

Existem wetlands de origem natural e construídas. Wetlands naturais é a denominação que se dá para áreas alagadas como as várzeas, brejos, pântanos, manguezais, entre outros encontrados na natureza e as construídas são utilizadas como sistemas naturais de tratamento de efluente com intuito de diminuir em padrões mínimos exigidos, a carga orgânica de um efluente ${ }^{2}$.

O projeto teve como objetivo avaliar o desempenho de duas wetlands com diferentes espécies de macrófitas (Canna $x$ Generalis - biri e Zantedeschia aethiopica - copo de leite) e um sistema controle constituído de cacos de telhas, construídas em escala experimental, como pós tratamento de um reator UASB na remoção de fósforo, instalado no campus da Faculdade de Tecnologia - Unicamp, Limeira - SP. A partir dos resultados obtidos, realizou-se uma análise estatística através do programa 'Software R'.

Figura 1. Sistema de wetlands montado para experimento.

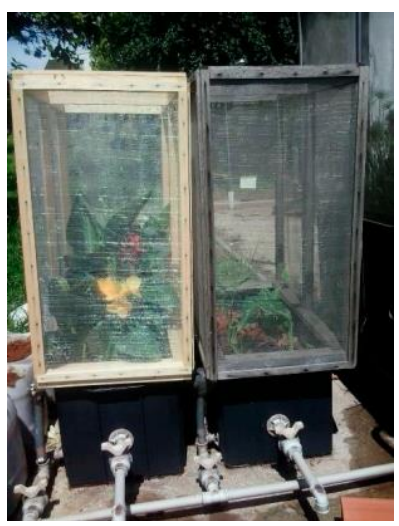

\section{Resultados e Discussão}

O resultado obtido para análise do fósforo está representado na Tabela 01.
Tabela 1. Valores das concentrações de Fósforo Total em mg. $\mathrm{L}^{-1}$ do pós tratamento na wetland.

\begin{tabular}{|c|c|c|c|}
\hline Data & Controle & Biri & Copo de Leite \\
\hline Coleta 1 & $68,93 \%$ & $40,11 \%$ & $61,58 \%$ \\
\hline Coleta 2 & $45,01 \%$ & $13,32 \%$ & $60,91 \%$ \\
\hline Coleta 3 & $63,32 \%$ & $40,61 \%$ & $72,05 \%$ \\
\hline Coleta 4 & $33,95 \%$ & $34,38 \%$ & $62,91 \%$ \\
\hline Coleta 5 & $56,58 \%$ & $52,63 \%$ & $74,34 \%$ \\
\hline Coleta 6 & $48,87 \%$ & $53,38 \%$ & $75,71 \%$ \\
\hline
\end{tabular}

Pode-se verificar que a macrófita copo de leite obteve melhor remoção que a biri e o controle, e ainda, a wetland sem vegetação - controle, também teve maior remoção que a biri.

Os resultados indicaram que não houve diferenças estatísticas o tratamento entre controle e biri. O tratamento da copo-de-leite comparado ao controle e biri apresentaram diferencas significativas. Portanto, com base nas análises estatísticas, o tratamento analisado com a macrófita copo-de-leite demonstrou maior eficiência na remoção de fósforo.

\section{Conclusões}

Baseado nas análises estatísticas, a macrófita que apresentou melhor eficiência na remoção de fósforo foi a copo-de-leite, apresentando uma melhor eficiência na remoção do nutriente, sendo a mais indicada para o pós tratamento de efluentes domésticos.

\section{Agradecimentos}

Agradeço à Prof. Dr. Marta S. G. Pires e à Prof. Dr. Elaine C. C. Poletti pelo carinho e atenção durante todo o decorrer do projeto, como também à Úniversidade Estadual de Campinas por permitir que o mesmo fosse realizado. PIBIC:CNPq pela bolsa.

\footnotetext{
${ }^{1}$ Salati, E. Controle de Qualidade de água através de sistemas de "wetlands" construídos. 19 f. FBDS - Fundação Brasileira para o Desenvolvimento Sustentável, Rio de Janeiro, 2011
}

${ }^{2}$ Borges, A. K. P. Despoluição de águas superficiais e efluentes de piscicultura através de sistemas construídos de áreas alagadas. Universidade Estadual Paulista. Instituto de Biociências. Rio Claro/SP. 140 p. 2005. 